SAKURA VOL. 1. No. 2 Agustus 2019

P-ISSN: 2623-1328

DOI : JS.2019. v01.i02. p01

E-ISSN:2623-0151

\title{
Analisis (kimochi, kibun, dan kigen ) dalam Novel Kitchin karya Banana Yoshimoto: Kajian Sintaksis Dan Semantik
}

Felicia Aprilani

Prodi Bahasa Jepang FB, Universitas Widyatama, Bandung, Jawa Barat, Indonesia e-mail: Felicia.aprilani@widyatama.ac.id

\begin{abstract}
In this study the authors analyzed the form and function of expressions of heart in Japanese kimochi, kibun and kigen. The purpose of this study is to discrete the form and function of kimochi, kibun and kigen in the sentence contained in Banana Yoshimoto's kitchin novel through the study of form and function.

In this study the author uses descriptive analysis method according to Sudaryanto's theory. According to the method of descriptive analysis is research carried out solely based on facts or phenomena that are empirically used by speakers so that it can be presented as is. For data analysis, the writer uses the method, namely the basic technique for Direct Elements (BUL). To analyze the data, the author uses the theory of Kyosuke Kandaichi and his friends. Based on the theory, it can be known the function of kimochi noun, kibun and kigen is to express the element of feeling that has the characteristics of each.
\end{abstract}

a.心 の 状態 (kokoro no jyoutai)

Kimochi function states about mood. Consider the following data:

さんざんな気持ちでなのののののチャイム。。。。

Sanzan na kimochide Tanabe ie no doachaimu wo oshita. (K: 79)

'With a feeling of chaos, I pressed the doorbell of the Tanabe family apartment'.

In the data above the sanzan na kimochi sentence shows a mood of chaos, when pressing the doorbell of the Tanabe family apartment.

Keywords: noun, form and function 


\begin{abstract}
Abstrak
Pada penelitian ini menganalisis bentuk dan fungsi ungkapan perasaan hati dalam bahasa Jepang kimochi, kibun dan kigen. Tujuan penelitian ini adalah untuk mendiskrispsikan bentuk dan fungsi kimochi, kibun dan kigen dalam kalimat yang terdapat di dalam novel kitchin karya Banana Yoshimoto melalui kajian bentuk dan fungsi.
\end{abstract}

Dalam penelitian ini penulis menggunakan metode analisis deskriptif menurut teori Sudaryanto. Menurut metode analisis deskriptif adalah penelitian yang dilakukan semata-mata hanya berdasarkan fakta atau fenomena yang memang secara empiris masih digunakan oleh penuturnya sehingga dapat dipaparkan apa adanya. Untuk analisis data penulis menggunakan metode agih yaitu teknik dasar Bagi Unsur Langsung (BUL). Untuk menganalisis data, penulis menggunakan teori Kyosuke Kandaichi dan kawan-kawan. Berdasarkan teori tersebut dapat diketahui makna nomina kimochi, kibun dan kigen adalah menyatakan unsur perasaan hati yang mempunyai ciri khas masing-masing.

a. 心の状態 (Kokoro no Jyoutai)

Kimochi fungsinya menyatakan tentang suasana hati. Perhatikan data berikut:

さんざんな気持ちでたなべ家のドアチャイムを押した。

Sanzan na kimochide Tanabe ie no doachaimu wo oshita. (K: 79)

'Dengan perasaan kacau balau, aku menekan bel pintu apartemen keluarga Tanabe'.

Pada data di atas kalimat sanzan na kimochi menunjukkan suasana hati yaitu suasana hati yang kacau balau, pada saat menekan bel pintu apartemen keluarga Tanabe.

Kata kunci: nomina, bentuk dan fungsi

\title{
1. PENDAHULUAN
}

Bahasa merupakan jati diri suatu bangsa, setiap bangsa di dunia mempunyai bahasanya sendiri. Apabila berkomunikasi dengan orang asing harus mengetahui pula bahasa orang tersebut. Jika tidak akan berjalan secara baik dan lancar.

Menurut Hirai dalam Sudjianto (1992 : 156) meishi (nomina) adalah katakata yang menyatakan nama suatu perkara, benda, barang, kejadian atau peristiwa, 
keadaan, dan sebagainya yang tidak mengalami konjugasi. Meishi disebut juga taigen. Di dalam suatu kalimat meishi dapat menjadi subjek, predikat, kata keterangan, dan sebagainya.

Dalam kaitan dengan penelitian ini penulis lebih memfokuskan pada nomina kimochi, kibun, dan kigen karena ketiga kata benda tersebut sama-sama mempunyai arti perasaan. Menurut https://kbbi.web.id/perasaan mempunyai pengertian: (1) hasil atau perbuatan merasa dengan pancaindera (2) rasa atau keadaan batin sewaktu menghadapi (merasai) sesuatu (3) kesanggupan untuk merasa atau merasai (4) pertimbangan batin (hati) atas sesuatu; pendapat.

Nomina kimochi, kibun, dan kigen mempunyai arti yang sama yaitu samasama menyatakan ungkapan perasaan hati. Jadi, nomina kimochi, kibun, dan kigen termasuk dalam sinonim. Menurut Kyosuke Kindaichi (1995) pengertian sinonim adalah:

類義語 : 同じ言語の中で音は違うが意味近い語。

Ruigigo: Onaji gengo no nakade oto wa chigau ga imi no chikai go

'Sinonim: Bunyi yang berbeda dalam bahasa yang sama, tetapi artinya mendekati/sama'.

Dalam The Great Japanese Dictionary nomina kimochi, kibun, dan kigen mempunyai pengertian seperti:

1. 気持ち：物事に対して感じる心の状態。

Kimochi: monogoto nitaishite kanjiru

'Kimochi adalah keadaan perasaan hati terhadap suatu hal'.

例：老人の気持ちを大切にする。

Roujin no kimochi wa taisetsu nisuru.

'Mementingkan perasaan orang tua'.

2. 気分：ある期間持続する勘定の状態。

Kibun : aru kikan jizokusuru kanjyou no jyoutai.

'Kibun adalah keadaan perasaan yang dirasakan dalam suatu waktu yang terus-menerus'.

気分：気分が変わる。

Kibun ga kawaru. 


\section{8 | Felicia Aprilina}

'Perasaan berubah'.

3. 機嫌 : 気持ち。気分。

Kigen : kimochi. Kibun.

'Kigen: menjelaskan tentang suasana hati'.

例：期限がよい。

Kigen ga yoi.

'Perasaan bagus/senyum-senyum'.

Pada penelitian ini penulis memfokuskan untuk meniliti ungkapan perasaan hati kimochi, kibun, dan kigen. Oleh karena itu, ada beberapa contoh dari nomina kimochi, kibun dan kigen dalam nihongo dai jiten:

1. 船酔いで気持ちが悪い。

Funayoi de kimochi ga warui.

'Perasaan tidak enak karena mabuk laut'.

2. 気分がすっきりしない。

Kibun ga sukkarishinai.

'Setelah bertengkar sama sekali tidak merasakan'.

3. 機嫌が悪い。

Kigen ga warui.

'Perasaan yang buruk/marah'.

Dari contoh ketiga di atas dapat dilihat ada kata kerja, kata sifat yang muncul di depan atau di belakang nomina kimochi, kibun dan kigen. Pada data (1) di atas nomina kimochi diikuti oleh kata kerja funayoi yang artinya mabuk laut, fungsinya untuk menguatkan kata kimochi. Pada data (2) di atas nomina kibun diikuti oleh kata kerja shikkarishinai yang artinya setelah bertengkar sama sekali tidak merasakan, fungsinya untuk menguatkan kata kibun. Begitu juga pada data (3) di atas nomina kigen diikuti oleh kata benda warui yang artinya marah/tersinggung, kata benda warui fungsinya menguatkan kata kigen.

Berdasarkan ketiga contoh di atas alasan penulis tertarik untuk meniliti ungkapan perasaan hati kimochi, kibun dan kigen dalam novel Kitchin karya 
Banana Yoshimoto adalah karena ketiga ungkapan ini mempunyai arti yang sama. Alasan penulis memilih novel Kitchin karya Banana Yoshimoto adalah karena di dalam novel tersebut terdapat kosakata yang bervariasi dan tema dari cerita novel tersebut sangat menarik.

\section{LANDASAN TEORI}

Dalam suatu penelitian, diperlukan suatu kajian atau landasan teori untuk menganalisis permasalahan. Untuk itu penulis menggunakan teori sebagai berikut:

1) Menurut Kandaichi (1995) dkk mengemukakan makna sebagai berikut:

1. 気持ち

a. 心にいただいているもの

Kokoro ni itadaite iru mono

'Sesuatu hal yang ada di hati'

Contoh: 他人の気持ちを尊重する

Tannin no kimochi wo sonchousuru

'Menghormati perasaan orang lain'

b. 心の状態

Kokoro no jyoutai

'Suasana hati'

Contoh: 愉快な気持ちになる

Yukai na kimochi ni naru

'Perasaan menjadi gembira'

c. 体の状態に心がまえ

Karada no jyoutai ni kokoro ga mae

'Suatu sikap terhadap keadaan tubuh'

Contoh: 気持ちが悪く、吐き気化する

Kimochi ga waruku, haki kikasuru

2. 気分

a. 心待ち

Kokoro machi

'Perasaan hati'

Contoh: 気分が転換 
Kibun tankan

'Menukar rasa hati'

b. 気性

Kisyou

'Sifat'

Contoh: 気分のいい人

Kibun no ii hito

'Orang yang mempunyai sifat baik'

c. おもむき

Omomuki

'Hasrat hati/keinginan'

Contoh: 夜の気分を出す

Yoru no kibun wo dasu

'Keinginan pada malam hari'

3. 機嫌

a. 愉快、深いの気持ち

Yukai, fukai no kimochi

'Perasaan senag dan tidak senang'

Contoh: 機嫌のよしあし

Kigen no yoshi ashi

'Perasaan baik dan buruk'

b. 安否

Anpi

'Keselamatan'

Contoh :手紙で機嫌をうかがう

Tegami de kigen wo ukagau

'Dengan surat perasaan terselamatkan'

c.「ご」をつけて気持ちのよいこと

Go wo tsukete kimochi no yoi koto desu

'Jika dilekatkan dengan go, keadaan baik atau perasaan baik'

Contoh: 酒を読んでご機嫌だ

Sake wo nonde gokigen

'Keadaan baik dengan minum sake' 
Berdasarkan teori Kandaichi (1995) di atas dapat diketahui bahwa kimochi, kibun dan kigen mempunyai makna:

A. Kimochi:

1. Sesuatu hal yang ada di hati

2. Suasana hati

3. Suatu sikap terhadap keadaan tubuh

B. Kibun :

1. Perasaan hati

2. Sifat

3. Hasrat hati

C. Kigen:

1. perasaan senag dan tidak senang

2. keselamatan

3. jika dilekatkan dengan go, keadaan baik atau perasaan baik

Berdasarkan teori Kyousuke Kandaichi inilah penulis akan menganalisis nomina kimochi, kibun, dan kigen dalam novel Kitchin karya Banana Yoshimoto pada bab III

\section{METODE PENELITIAN}

Metode yang digunakan dalam penelitian ini adalah analisis deskriptif. Metode analisis deskriptif dilakukan semata-mata hanya berdasarkan fakta yang ada atau fenomena yang memang secara empiris masih digunakan oleh penuturnya, sehingga dapat dipaparkan apa adanya (Sudaryanto, 1992:62). Tujuan dari penelitian deskriptif adalah untuk membuat deskriptif, gambaran atau lukisan secara sistematis, factual dan akurat mengenai fakta-fakta, sifat-sifat serta hubungan antar sesame fenomena yang diselidiki.

Metode analisis deskriptif merupakan istilah umum yang mencakup berbagai teknik, deskriptif di antaranya adalah penelitian yang memaparkan, menganalisis, dan mengklasifikasi data yang telah diperoleh. Dalam 


\section{2 | Felicia Aprilina}

pelaksanaannya, metode deskriptif tidak terbatas hanya sampai pengumpulan data dan penyusunan data saja, tetapi meliputi analisis dan arti dari data itu sendiri.

\subsection{Teknik Penyedian Data}

Dalam penyediaan data pada penelitian ini penulis menggunakan metode simak yaitu metode pengumpulan data yang dilakukan dengan menyimak penggunaan bahasa (Sudaryanto, 1993:113). Metode simak dilakukan dengan cara menyimak kalimat-kalimat yang berhubungan dengan struktur ungkapan perasaan hati kimochi, kibun, dan kigen yang terdapat dalam novel Kitchin karya Banana Yoshimoto. Setelah melakukan metode simak, diterapkan teknik catat Sudaryanto (1993:135) teknik catat adalah pencatatan yang dilakukan pada kartu yang segera dilanjutkan dengan klasifikasi. Teknik catat ini dimaksudkan agar data yang diperoleh melalui metode simak dapat dikumpulkan dan diklasfikasikan sesuai dengan kelompoknya masing-masing.

\subsection{Teknik Analisis Data}

Dalam metode ini penulis menganalisis data dengan mempergunakan metode agih. Menurut Sudaryanto (1993:15). Metode agih adalah metode yang menggunakan alat penentu bagian dari bahasa yang bersangkutan yang menjadi objek sasaran di dalam penelitian itu sendiri. Dalam penelitian ini penulis membahas ungkapan perasaan hati nomina kimochi, kibun dan kigen, di antara sekian banyak jenis ungkapan perasaan dalam bahasa Jepang dan yang menjadi objek sasaran di dalam penelitian ini adalah ungkapan perasaan hati nomina kimochi, kibun, dan kigen.

Metode agih ini dilakukan degan teknik dasar. Dalam penelitian ini penulis menggunakan teknik dasar. Teknik dasar dengan menggunakan teknik bagi unsur langsung (BUL) dan unsur-unsur yang bersangkutan dipandang sebagai bagian langsung membentuk satuan lingual yang dimaksud (Sudaryanto, 1993:31).

Dalam penelitian ini penulis menggunakan novel Kitchin karya Banana Yoshimoto. Setelah data yang terdiri dari ungkapan perasaan hati kimochi, kibun, dan kigen terkumpul, kemudian data tersebut diolah dengan cara mencari arti setiap 
kalimat yang terdiri dari ungkapan perasaan hati kimochi, kibun, dan kigen kemudian data tersebut dikelompokkan sesuai dengan struktur karena dalam penelitian ini penulis lebih menitikberatkan kepada kajian struktur. Ungkapan perasaan hati yang terdiri dari kimochi, kibun, dan kigen masing-masing menjelaskan tentang perasaan atau suasana hati yang sedang dirasakan. Kemudian tergantung masing-masing orang yang mengalami.

(4) 私はしみじみした気持ちで友達の名前をずった。(K:46)

Watashiwa shimijimi shita kimochi de tomodachi no namae wa tsuzutta.

'Dengan perasaan yang mendalam, aku menuliskan nama teman-temanku'.

Pada data (4) di atas kata kimochi didahului oleh kata kerja shimijimishita. Kata shimijimishita menguatkan kata kimochi membentuk satu kesatuan ungkapan yang menyatakan perasaan yang dimiliki hati. Penggunaannya untuk diri sendiri ditandai dengan kata ganti orang pertama watashi 'saya', karena menuliskan nama teman-temannya, teringat masa lalu.

(5) 私はの胸を肉をえぐりとれたような気分になった。(K:75)

Watashi wa mune wo niku wo eguri torareta youna kibun ni natta.

'Seperti rasanya daging di dadaku dicukil keluar'.

Pada data (5) di atas kata kibun diikuti oleh kalimat mune no niku wo eguri torareta youna 'seperti mencukil daging di dada'. Kata mune wo niku wo eguri torareta youna menguatkan kata kibun "perasaan" jadi kata mune wo niku wo eguri torareta youna (seperti daging didadanya dicukil keluar) dan kibun membentuk satu kesatuan ungkapan yang menyatakan perasaan hati yang pedih. Penggunaan perasaan pedih ini untuk diri sendiri ditandai dengan kata ganti orang pertama watashi 'saya' merasakan perasaan pedih yang menyakitkan seperti daging di dadanya dicukil keluar. 


\section{4 | Felicia Aprilina}

\section{PEMBAHASAN}

\section{1 気持ち(Kimochi)}

Berikut analisis kimochi, kibun, dan kigen dari segi makna dan fungsi sebagai berikut:

b. 心にだいているもの(kokoro ni daitei iru mono)

Kimochi maknanya menyatakan suatu hal yang ada di hati. Perhatikan data berikut:

[6] あまりにも不確かな時間や気持ちの流れの中で、五感にはい ろいろな歴史が刻みことまれている。(K:119)

Amari nimo futashi ka na jikan ya kimochi no nagare no naka de, gokan niw iro iron a rekishi ga kizami koto marete iru.

'Dalam aliran perasaan dan waktu yang tidak menentu, kelima panca inderaku telah teriri-iris oleh berbagai kejadian masa lalu'.

Pada data (6) di atas perasaannya ini ditunjukkan nomina kimochi yang terdapat kalimat kimochi no nagare. Kalimat kimcohi no nagare menunjukkan suatu hal yang ada di hati yaitu suatu perasaan yang timbul karena dalam aliran perasaan dan waktu yang tidak menentu, Mikage merasa kelima panca inderanya telah teriris-iris oleh berbagai kejadian masa lalu. Pada kalimat di atas nomina kimochi diikuti oleh kalimat yaitu amari futashi ka na jikan ya.

Nomina kimochi tersebut tidak bisa digantikan dengan kata yang mengacu keperasaan lainnya seperti kibun dan kigen tidaklah berterima, karena bila digantikan dengan nomina kibun tidak menunjukkan situasi moodnya, keinginan maupun pemikiran. Sedangkan nomina kigen juga tidak menunjukkan perasaan yang berhubungan dengan orang lain.

\section{c. 心の状態 (Kokoro no Jyoutai)}

Kimochi maknanya menyatakan tentang suasana hati. Perhatikan data berikut: 
さんざんな気持ちでたなべ家のドアチャイムを押した。

Sanzan na kimochide Tanabe ie no doachaimu wo oshita. (K: 79)

'Dengan perasaan kacau balau, aku menekan bel pintu apartemen keluarga Tanabe'.

Pada data di atas kalimat sanzan na kimochi menunjukkan suasana hati yaitu suasana hati yang kacau balau, pada saat menekan bel pintu apartemen keluarga Tanabe.

\section{気分(Kibun)}

a. 心待ち (Kokoro Machi)

きっとその時も気分が悲しい暗い気分の中を生きているだろう、 そのことが心からいやだった。(K:78)

Kitto sono toki mo jibun ga kanashii kurai kibun no naka wo ikiteiru darou, sono koto ga kokoro kara iya data.

'Sejujurnya aku benci dengan hal itu kenyataan bahwa ketika itu juga aku akan hidup dalam perasaan nelangsa'.

\section{機嫌 (Kigen)}

a. 愉快、深いの気持ち (yukai, fukai no kimochi)

Kigen yang maknanya menyatakan perasaan senang dan tidak senang. Perhatikan data berikut:

[1] 部屋を暗くて、何しないでボオりしてるの。でも私がいろなん ことを知りたがったりすると、彼は不機嫌になったり怒ったり するの。(NW:265)

Heya wo kurakute, nani mo shinai de botsu toshiteru no. Demo watashi ga iron nan kotow o shirita gattari suru to, kare wa fukigen ni nattari okottari suru no. 


\section{6 | Felicia Aprilina}

'Tidak ingin melakukan apapun di kamar yang gelap. Tetapi begitu saya ingin mengetahui berbagai macam hal, dia merasa tidak senang dan marah'.

Pada data di atas nomina kigen yang terdapat pada kalimat kare wa fukigen. Kalimat fukigen menunjukkan perasaan yang tidak senang karena ketika saya ingin mengetahui berbagai macam hal, tetapi dia merasa tidak senang dan marah.

\section{SIMPULAN}

Kimochi, kibun, dan kigen mempunyai arti yang sama dan sama-sama menunjukkan yang berhubungan dengan perasaan (secara leksikal) namun secara gramatikal dalam konteks sebuah kalimat maknanya berbeda. Ciri khas lainnya kimochi menunjukkan mood, harapan, dan berhubungan dengan indera perasa. Kibun menunjukkan physicologi atau kejiwaan. Kigen menunjukkan apabila ada hubungannnya dengan orang lain dan menjukkan kondisi tubuh yang sakit.

\section{DAFTAR PUSTAKA}

Chaer, Abdul. Drs. 2003. Linguistik Umum. Jakarta : Rineka Cipta

https://kbbi.kemdikbud.go.id/

Murakami, Haruki. 1991. Norwegian Wood. Japan

Nihongo Dai Jiten, 1995. Kondansha

Sari, Vanila. 2008. "Ungkapan Saran Dalam Novel Kokoro Kajian Semantik".

Padang: Universitas Bung Hatta

Kokugo Dai Jiten, 1995. Kondansha

Sudaryanto. 1992. Metode Linguistik. Yogyakarta : Gajah Mada University Press 1993. Metode dan Aneka Teknik Analisis Bahasa. Yogyakarta: Duta Wacana University Press

Sudjianto. 2003. Gramatika Bahasa Jepang Modern. Bekasi : Kesaint Blanc 
Yoshimoto, Banana. 1989 . Kitchin. Japan : Fukushikishoten

Matsura, Kenji. 1994. Kamus Jepang-Indonesia. Japan : Kyoto Sangyo University

Tanimori, Masahiro.2007. Buku Panduan Tata Bahasa Jepang. Yogyakarta : Quills 